\title{
In vitro investigation of orange fleshed sweet potato prebiotic potential and its implication on human gut health
}

\author{
Mary N. Muchiri, ${ }^{1,2}$ and Anne L. McCartney ${ }^{1}$
}

${ }^{1}$ Food Microbial Sciences Unit (FMSU), Department of Food and Nutritional Sciences, University of Reading, RG6 6AP, Reading, United Kingdom; ${ }^{2}$ Department of Food Science and Nutrition, Karatina University, PO Box 1957 -10101, Karatina, Kenya

Corresponding author: Muchiri Mary (PhD). Karatina University. Po Box 1957-10101, Karatina, Kenya.

Submission Date: May 10 ${ }^{\text {th }}$, 2017, Acceptance Date: October $28^{\text {th }}$, 2017, Publication Date: October $31^{\text {st }}, 2017$

Citation: Muchiri M.N., McCartney A.L., In vitro investigation of orange fleshed sweet potato prebiotic potential and its implication on human gut health. Functional Foods in Health and Disease 2017; 7(10): 833-848. https://doi.org/10.31989/ffhd.v7i10.361

\begin{abstract}
Background: Some food ingredients (prebiotics) have been shown to promote a healthy gut by selectively stimulating growth/activity of beneficial gastrointestinal microbes and metabolites such as short chain fatty acids (SCFA) while inhibiting pathogens. Orange fleshed sweet potato (Ipomoea batatas Lam; OFSP) root tuber is a starchy tropical crop and highly nutritious in terms of provitamin A (beta carotene), dietary fibre, and natural sugars, with negligible amount of fats and cholesterol. The aim of the study was to investigate using simulated human gut system whether OFSP may have prebiotic activity derived from their fibre, resistant starch, and/or the sugars.
\end{abstract}

Methods: In vitro $\mathrm{pH}$ controlled stirred batch culture fermentation system was used to compare the effect on human gut microbiota of four substrates: two varieties of OFSP (SPK 004 and Tainung), FOS and sucrose known for positive prebiotic and non-selective change respectively. The system was inoculated with faecal slurry from six different human healthy donors from different ethical backgrounds, age, and the effectual change recorded over 24 hours by monitoring bacterial counts (total bacteria, Bacteroides and Bifidobacterium) using qPCR molecular technique and SCFA profiles by gas chromatography.

Results: The total bacteria count increased by (0.92-1.7 $\log 10)$ and Bacteroides genus (1.03-1.8 $\log 10)$ throughout the experimental period but with no significant differences $(p<0.05)$ between the four substrates. However, there were significant differences $(\mathrm{p}<0.05)$ in the beneficial Bifidobacterium 
(1.66-2.66 $\log 10)$ between the 2 varieties of OFSP and the two controls (FOS and sucrose). The levels of SCFA increased, with acetate as the predominant acid and lactic acid being the least. The OFSP purees elicited high butyric acid levels, which were comparable to those of positive control FOS.

Conclusion: The study demonstrated that OFSP purees may have prebiotic potential that can positively modulate gut microbiota by promoting growth of beneficial bacteria, bifidobacterium genus, and stimulating production of SCFA especially butyric acid which is the favourable in human gut health. However, further research using more probiotic and pathogenic microbes in addition to in vivo clinical studies and compositional analysis of OFSP is needed to confirm prebiotic activity.

Keywords: Orange fleshed sweet potato, prebiotic, human gut microbiota

\section{BACKGROUND}

Consumption of foods rich in whole-grains, wild species of fruit, vegetables, seeds, root tubers, and gums which are rich in dietary fibre, oligosaccharides, inulin, and other complex polysaccharides have been shown to promote a healthy gut by increasing the relative abundance of bifidobacteria/lactobacillus and other butyrate-producing bacteria. While diets high in animal protein (particularly red and processed meats), eggs, protein, alcohol, energy, fat, sulphur, and sulphate have been linked to the negative modulation of colon microbial population and/or metabolisms by increasing the concentration of pathogenic microbes and toxinogenic metabolites [1-5]. Dietary prebiotic, the term used to define 'food ingredient(s) that are selectively fermented in the gut resulting in specific changes in the composition and/or activity of the gastrointestinal microbiota, thereby conferring benefit(s) upon host health,' are resistant to digestion by human enzymes and absorption in the small intestines but are fermentable/metabolized by some colon bacteria to produce beneficial metabolites. Fructooligosaccharide (FOS) is one of the prebiotic carbohydrates that have been proven in vitro and in vivo to have prebiotic activity by increasing levels of beneficial microbes especially bifidobacteria, thereby causing a healthier human colon [6-7]. Synbiotic, mixtures of prebiotics and probiotics (live beneficial microorganisms), in functional foods have been developed to improve the survival and implantation of probiotics in the human gut system [8].

From a nutritional point of view and perspective, orange fleshed sweet potato (OFSP) tubers were ranked from as number one among all vegetables [9-10], although they are also known to cause flatulence in some individuals when consumed in large quantities like other well-known prebiotic whole foods. This may be due to digestion resistance of some of its constituents by enzymes in human upper gastrointestinal tract which on proceeding to the colon are fermented by microbes producing the flatulence gases [11-14]. Several variety/cultivar of OFSP tubers have been developed [15] whose composition vary significantly depending on age of root [16], climatic conditions [17], and soil fertility [18]. 
Saccharolytic and proteolysis are the two main types of colonic microbial fermentation which mainly occur in the proximal and distal colon respectively [19-22]. The principal substrates for saccharolytic metabolism are non-digestible carbohydrates including oligosaccharides, gums, resistant starches, cellulose, hemicellulose, pectins, unabsorbed sugars, and alcohols, which on fermentation increases the relative abundance of desirable butyrate and other short-chain fatty acids (SCFA), organic acids such as lactate, vitamins producing bacteria and gases $\left(\mathrm{CO}_{2}, \mathrm{CH}_{4}, \mathrm{H}_{2}\right.$ and $\mathrm{H}_{2} \mathrm{~S}$ ) that acidify the colon [23-27]. The acidic environment promotes proliferation of beneficial bacteria population such as bifidobacteria and/or lactobacilli [28-29], in addition to increasing mineral bioactivity and absorption [30-31]. Proteolytic fermentation promote growth of pathogenic bacteria, such as some species of Bacteroides and Clostridium, which produce toxigenic microbial metabolites (nitrogenous compounds e.g. ammonia amines, phenol substituted fatty acids, and hydrogen sulphide) and/or carcinogenic/genotoxic comounds that cause molecular receptor decoying, thereby inhibiting bacterial adhesion and antibiotic-associated diarrhoea [3233] The majority of SCFA (acetate, propionate, and butyrate) and lactate are absorbed into the blood stream and can be further metabolized in the liver, muscle, brain, or other peripheral tissues, contributing to host daily energy requirements [34-35]. Acetate is mainly metabolized in human muscle, kidney, heart, and brain, while propionate is utilized primarily in the liver and has been suggested to be a potential modulator of cholesterol synthesis and a precursor in liponeogenesis, which may influence body weight. Butyrate is the preferred energy source for colonic epithelial cells and has been shown to stimulate apoptosis in the colon and is suggested to have anti-tumor properties that provide protection against cancer [36-37]. Non-digestible carbohydrates have the added health benefit of increasing stool bulk, which influences colonic transit times by increasing peristalsis and preventing constipation [38]. Clinical studies show that certain illnesses or metabolic dysfunction such as type-2 diabetes, obesity, atherosclerosis/hypertension, ulcerative colitis, cardiovascular diseases, colorectal cancer, Crohn's disease, inflammatory bowel disease (IBD), and some allergies have been linked with alterations in composition and functions of the normal gut microbiota [39-42].

The study therefore investigated whether OFSP tuber has prebiotic activity that may positively influence human gut by modulating the microbiota towards proliferation of the healthy bacteria and production of SCFAs during metabolism.

\section{MATERIALS AND METHODS}

Two varieties of OFSP tubers, SPK 004 (Rp) and Tainung (Op) sourced from Kenya Agricultural Research Institute, Embu Center, were used to prepare the purees at University of Reading, Food Pilot Plant whereby approximately $500 \mathrm{~g}$ medium sized tubers were boiled at temperature below $70^{\circ} \mathrm{C}$ for 30 minutes until soft, peeled, and pulped immediately while still warm [43]. Four $120 \mathrm{ml}$ glass batch culture fermentation vessels each containing $90 \mathrm{ml}$ of pre-reduced gut model media (GMM), set to simulate human gastrointestinal (GI) colon conditions in terms of temperature $\left(37^{\circ} \mathrm{C}\right), \mathrm{pH}(6.85)$ and maintained anaerobic by continuous sparging with oxygen-free nitrogen were inoculated with $10 \mathrm{ml}$ of human faecal homogenate slurry using sterile syringes. The $\mathrm{pH}$ of 
each vessel was controlled automatically by the addition of $1 \mathrm{M} \mathrm{HCl}$ or $1 \mathrm{M} \mathrm{NaOH}$ using Electrolab $\mathrm{pH}$ controllers and temperature by circulating water bath while continuously stirring the vessels. The GMM comprised of ( $\mathrm{g} / 440 \mathrm{ml}$ heated distilled water): starch from potato, 2.2; pectin from citrus fruits, 0.88; gum arabic, 0.44; xylan from oatspelts, 0.88; arabinogalactan from larchwood, 0.88; inulin, 0.44; caesin from bovine salts, 1.32; peptone water, 2.2; tryptone 2.2; bile salts, 1.76; yeast extract, 1.98; iron sulfate heptahydrate, 0.0022; sodium chloride, 1.98; potassium chloride, 1.98; potassium phosphate monobasic, 0.22 ; magnesium sulfate heptahydrate, 0.55 ; calcium chloride hexahydrate, 0.066, sodium bicarbonate, 0.66; L-cysteine $\mathrm{HCl}, 0.352$; porcine gastric mucin (type III), 1.76; and $4.4 \mathrm{ml}$ of haemin solution $(0.5 \mathrm{mg} / \mathrm{ml})$. All components of the GMM were combined and autoclaved at $121{ }^{\circ} \mathrm{C}$ for 15 minutes. The four substrates were each added to the 4 vessels: $1 \mathrm{~g}$ sucrose (non-selective control); $1 \mathrm{~g}$ FOS (positive control); and the rest 2 vessels $2.5 \mathrm{~g}$ of OFSP purees (Rp and Op) that achieves the required daily intake (RDI) of 600 RAE. The final working volume of each batch culture vessel was $100 \mathrm{ml}$ [44]. Samples were collected (on ice) in triplicate immediately after inoculation $\left(\mathrm{T}_{0}\right)$ and after 5, 10, and 24 hours for bacterial enumeration and SCFA analysis. Six separate batch fermentation runs were performed with different healthy faecal donor for each run.

\section{Preparation of human faecal inoculum}

Mixed microbial inoculum (faecal homogenate) were prepared from fresh faecal samples of six healthy human volunteers with no history of gastrointestinal disorders and who had not taken antibiotics for at least three months prior to the study. Donors were aged 20-55 yr; 2 males (1 Chinese and 1 Mexican) and 4 females (2 Chinese, 1 British, and 1 African). The volunteers were each supplied with a stool collection kit (white plastic pot containing stomacher bag, Anaerocult jar, and Anaerogen sachet [Oxoid Limited] which was used according the manufacturer's instructions to generate an anaerobic atmosphere). Fresh faecal samples were collected on the morning of the experiment, transported to the laboratory anaerobically and processed within 2 hours of defecation. The stool sample was manually kneaded, and faecal homogenate was then prepared by diluting a portion in 1:10 (w/w) in pre-reduced $0.1 \mathrm{M}$ phosphate-buffered saline (PBS; $\mathrm{pH}$ 7.3) and stomaching in a filter bag for 2 min at 'high' speed (Stomacher 400 Lab System; Sewards).

\section{Bacterial enumeration by $q P C R$}

\section{DNA extraction via phenol-chloroform method}

Aliquots $(1.5 \mathrm{ml})$ of each sample were immediately centrifuged $(13000 \mathrm{rpm}, 10 \mathrm{~min})$ to collect cell pellets, which were washed with $1 \mathrm{ml}$ PBS prior to storing in PBS:glycerol (1:1) at $-20^{\circ} \mathrm{C}$ for DNA extractions. PBS:glycerol samples were thawed on ice, centrifuged (13000 rpm, $5 \mathrm{~min}$ ) and cell pellets washed with $1 \mathrm{ml}$ of PBS prior to resuspension in $0.5 \mathrm{ml}$ of TES buffer and treatment with lysozyme $(8 \mu \mathrm{l}, 10 \mathrm{mg} / \mathrm{ml})$ and mutanolysin $(2 \mu \mathrm{l}, 1 \mathrm{mg} / \mathrm{ml})$ at $37^{\circ} \mathrm{C}$ for $30 \mathrm{~min}$. Proteinase $\mathrm{K}(10 \mu \mathrm{l}, 20 \mathrm{mg} / \mathrm{ml})$ and RNase $(10 \mu \mathrm{l}, 10 \mathrm{mg} / \mathrm{ml})$ were added to the suspension which was vortexed and incubated at $65^{\circ} \mathrm{C}$ for 1 hour before sodium dodecyl sulfate (SDS) treatment; $100 \mu \mathrm{l}$ 
of $10 \%$ SDS solution was added and the suspension gently mixed by inversion then incubated for a further $15 \mathrm{~min}$ at $65^{\circ} \mathrm{C}$. The suspension was cooled on ice for $30 \mathrm{~min}$ before phenol/chloroform extraction (1 volume phenol/chloroform/water [Applied Biosystems, UK] added, samples mixed by inversion for $2 \mathrm{~min}$ and centrifuged for $10 \mathrm{~min}$ at $6500 \mathrm{rpm}$ ). The upper aqueous layer was transferred to a clean, sterile microcentrifuge tube and $1 \mathrm{ml}$ of ice-cold ethanol added. The samples were stored overnight at $-20^{\circ} \mathrm{C}$ before centrifugation $(5 \mathrm{~min}$ at $13000 \mathrm{rpm}$ ) to collect the DNA pellet. The supernatant was carefully removed, and the DNA dried overnight at room temperature. DNA was eluted in $50 \mu$ l of sterile water subsequent to measuring concentration (ng/ $\mu \mathrm{l})$ by ND1000 Nanodrop spectophotometer and storing at $-20^{\circ} \mathrm{C}$.

\section{Quantitative PCR}

Quantitative PCR (qPCR) was performed on extracted DNA according to procedure [45] for universal (UniF-UniR), bacteroides (Bac303F-Bfr-Fmrev), and bifidobacteria (BifF-g-Bifid-R) using a BioRad miniOpticon and SsoAdvanced ${ }^{\mathrm{TM}}$ SYBR® Green Supermix (BioRad). Purified Bacteroides thetaiotaomicron DMS $2079^{\mathrm{T}} 16 \mathrm{~S}$ rRNA gene amplicons were used as the standard for universal and bacteroides qPCR and Bifidobacterium bifidum DMS 20456 ${ }^{\mathrm{T}} 16 \mathrm{~S}$ rRNA gene amplicons was used as the standard for bifidobacteria qPCR.

\section{Short chained fatty acids (SCFA) analysis by gas chromatography}

Aliquots $(1.5 \mathrm{ml})$ of fermentation samples were centrifuged $(13000 \mathrm{rpm}, 10 \mathrm{~min})$ and filtered supernatants stored at $-20^{\circ} \mathrm{C}$ for SCFA analysis. SCFAs were measured by derivatization method of fatty acids using gas chromatography equipped with a flame ionisation detector (HP-1 column (10 $\mathrm{mx} 0.53 \mathrm{~mm}$ IDx2.65 mm), carrier gas helium with a total flow rate of $37 \mathrm{~mL} / \mathrm{min}$ and pressure of $7 \mathrm{kPa}$, temperature $255-260^{\circ} \mathrm{C}$ and holding for $5 \mathrm{~min}$, pressure $15 \mathrm{kPa}$ and holding for $4 \mathrm{~min}$. The filtrates were thawed on ice and $1 \mathrm{ml}$ was mixed with $50 \mu \mathrm{l}$ of internal standard $(0.1 \mathrm{M} 2$ ethylbutyric acid) prior to derivatization. Standard organic acids mixtures as external standards were derivatized alongside the samples [46].

\section{Statistical analysis}

Genstat $16^{\text {th }}$ Edition statistical package (VSN International Ltd, University of Reading) was used for data analysis with substrates (FOS, sucrose, Op and Rp OFSP purees) and time (0, 5, 10 and $24 \mathrm{hr}$ ) as treatment factors. Means of analysis of variance (ANOVA) of SCFA concentration $(\mathrm{mM} / \mathrm{ml})$ and bacterial count which was transformed to $\log _{10}$ were conducted and Duncan's multiple range test was used for separation of means at $(p<0.05)$.

\section{RESULTS AND DISCUSSIONS}

\section{pH controlled in vitro batch fermentation of OFSP puree}

Overall variations were observed across the 6 different faecal donor runs, with relatively large standard deviations in bacterial counts and SCFA (Figure 1 and Table 1) due to broad differences 
in their ethnic backgrounds (British, 3 Chinese, Mexican and African), age (20-55 yr) and gender, thereby introducing variations in diet and phenotype/genotype. No consistent pattern was seen in relation to changes in qPCR bacterial populations, even between runs 3 and 4, which were inoculated with faecal from 2 Chinese females of the same age. The result is consistent with recent studies that reported variations of the subsequent metabolic fermentation trajectory due to differences of donors' inoculums, with high specificity at both species and strain level [47-48].

\section{Effects of OFSP puree batch fermentation on bacteria}

Total bacteria: Total bacteria increased throughout the fermentations by the end of the 24 hours fermentation period in all the 6 runs (Table 1). The maximum average change in total bacteria varied for the 4 different substrates (Table 3 ), but it remained relatively stable (0.92-1.7 $\log _{10}[$ copies/ml]) with no significant differences $(p>0.05)$.

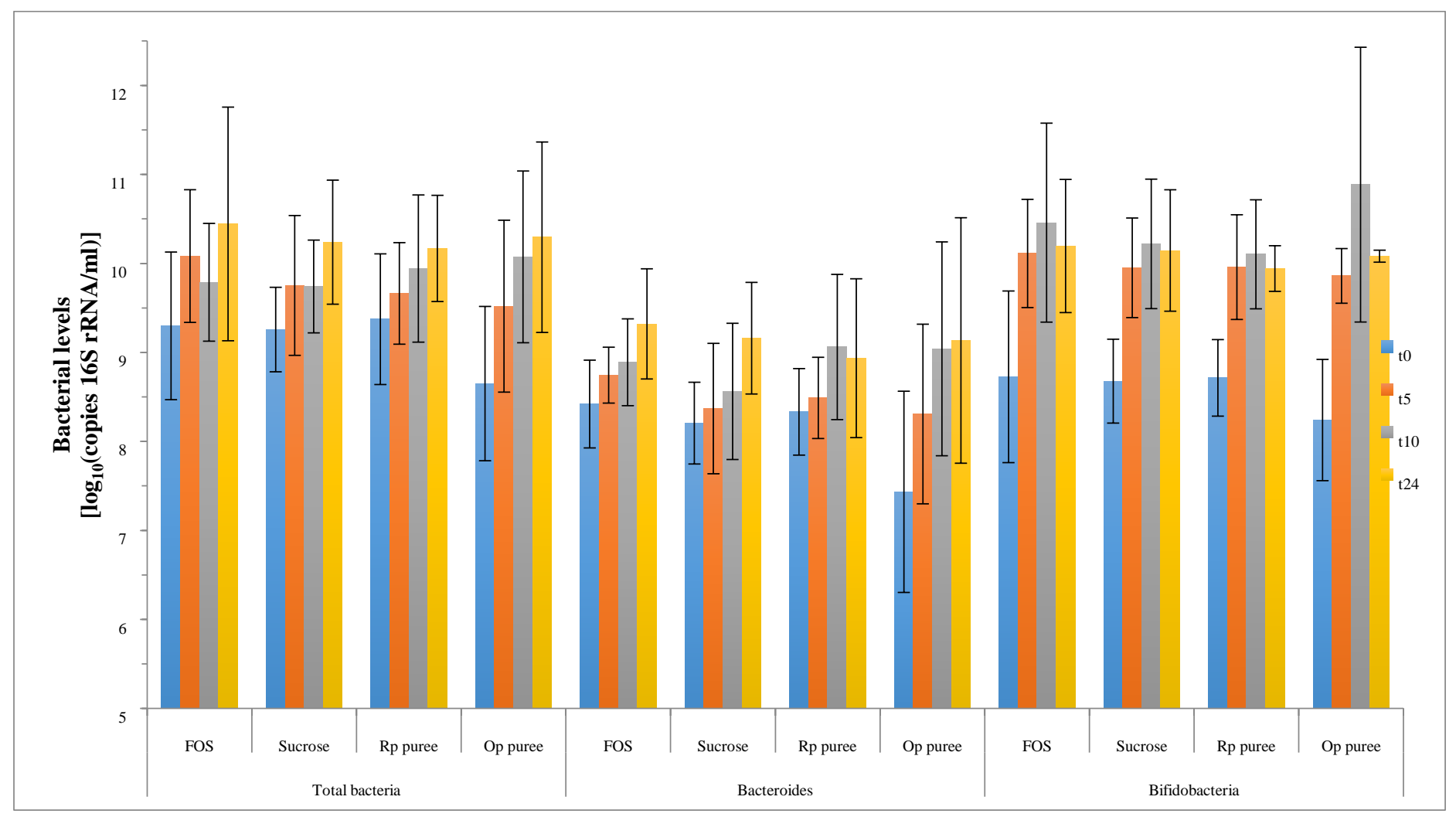

Figure 1. Investigation of the effects of OFSP purees on total bacteria, Bacteroides and Bifidobacterium populations during $\mathrm{pH}$ controlled in vitro batch fermentations. Data are presented as averages with SD (error bars) of six runs, each using a different donor. FOS was used as prebiotic control and sucrose as nonselective control for $24 \mathrm{hr}$ fermentations - blue, baseline (t0); red, t5; green, t10; and purple, t24. Rp, SPK 004; and Op, Tainung OFSP.

Bacteroides: Generally, the Bacteroides increased throughout the fermentation period although the highest levels were seen at $\mathrm{t} 5$ or $\mathrm{t} 10$ for some vessels/runs (Table 1). The highest count in the 6 runs was recorded in Op puree, run $1\left(3.3 \log _{10}[\operatorname{copies} / \mathrm{ml}]\right)$ which also recorded the highest average maximum change, although it was not significantly different between the substrates (Table 
3). Bacteroides have been reported to have a diverse array of substrate (polysaccharides) utilized during metabolism [49], which most likely explains the increase in levels on all substrates in this study. Our data concur with the findings from a previous study of green and gold kiwifruit, which showed the Bacteroides population increased between $\mathrm{t} 5$ and $\mathrm{t} 24$ although it subsequently dropped by $\mathrm{t} 48[50]$.

Table 2. SCFA concentrations $(\mathrm{mmol} / \mathrm{ml})$ during $\mathrm{pH}$ controlled batch fermentation of OFSP puree and control substrates

\begin{tabular}{|c|c|c|c|c|c|}
\hline \multirow{2}{*}{ SCFA } & \multirow{2}{*}{ Time (hr) } & \multicolumn{4}{|l|}{ Substrate } \\
\hline & & FOS & Sucrose & Rp puree & Op puree \\
\hline \multirow{4}{*}{ Total } & 0 & $5.07 \pm 0.88$ & $5.12 \pm 0.89$ & $4.83 \pm 0.79$ & $5.07 \pm 0.88$ \\
\hline & 5 & $43.13 \pm 7.79$ & $41.36 \pm 6.75$ & $51.59 \pm 7.89$ & $46.32 \pm 7.07$ \\
\hline & 10 & $75.84 \pm 12.92$ & $68.30 \pm 11.04$ & $66.12 \pm 10.54$ & $67.64 \pm 11.71$ \\
\hline & 24 & $103.13 \pm 16.60^{\mathrm{a}}$ & $93.24 \pm 14.95^{b}$ & $94.93 \pm 14.23^{b}$ & $92.58 \pm 14.76^{b}$ \\
\hline \multirow{4}{*}{ Formate } & 0 & $1.87 \pm 0.35$ & $1.77 \pm 0.22$ & $1.54 \pm 0.44$ & $1.73 \pm 0.62$ \\
\hline & 5 & $8.63 \pm 0.92$ & $8.79 \pm 2.26$ & $8.06 \pm 1.68$ & $7.69 \pm 1.57$ \\
\hline & 10 & $6.45 \pm 4.45^{\mathrm{a}}$ & $7.65 \pm 4.58^{\mathrm{b}}$ & $5.30 \pm 2.39^{c}$ & $3.13 \pm 1.85^{\mathrm{d}}$ \\
\hline & 24 & $2.91 \pm 2.24^{\mathrm{a}}$ & $2.89 \pm 2.22^{\mathrm{a}}$ & $3.31 \pm 1.93^{\mathrm{a}}$ & $1.83 \pm 0.64^{\mathrm{b}}$ \\
\hline \multirow{4}{*}{ Acetate } & 0 & $2.29 \pm 2.56$ & $2.40 \pm 2.79$ & $2.16 \pm 3.16$ & $2.41 \pm 3.16$ \\
\hline & 5 & $23.83 \pm 5.44^{\mathrm{a}}$ & $20.15 \pm 7.98^{b}$ & $23.31 \pm 9.14^{\mathrm{a}}$ & $19.56 \pm 6.44^{b}$ \\
\hline & 10 & $36.10 \pm 5.29^{\mathrm{a}}$ & $31.99 \pm 12.94^{\mathrm{b}}$ & $31.34 \pm 8.08^{b}$ & $32.77 \pm 6.68^{b}$ \\
\hline & 24 & $41.95 \pm 3.74$ & $37.44 \pm 11.33$ & $40.08 \pm 10.51$ & $38.85 \pm 5.29$ \\
\hline \multirow{4}{*}{ Propionate } & 0 & $0.16 \pm 0.05$ & $0.17 \pm 0.05$ & $0.16 \pm 0.05$ & $0.14 \pm 0.04$ \\
\hline & 5 & $0.16 \pm 3.09^{\mathrm{a}}$ & $0.14 \pm 2.14^{\mathrm{a}}$ & $3.52 \pm 2.69^{b}$ & $3.32 \pm 1.50^{\mathrm{b}}$ \\
\hline & 10 & $4.35 \pm 7.87^{\mathrm{a}}$ & $3.32 \pm 4.62^{\mathrm{a}}$ & $11.98 \pm 5.39^{b}$ & $12.31 \pm 4.25^{\mathrm{b}}$ \\
\hline & 24 & $18.28 \pm 6.09^{a}$ & $12.31 \pm 6.74^{b}$ & $18.28 \pm 8.77^{a}$ & $18.52 \pm 4.49^{a}$ \\
\hline \multirow{4}{*}{ Butyrate } & 0 & ND & $0.03 \pm 0.07$ & ND & ND \\
\hline & 5 & $6.61 \pm 5.97^{\mathrm{a}}$ & $7.19 \pm 4.69^{\mathrm{a}}$ & $2.85 \pm 10.30^{\mathrm{b}}$ & $12.63 \pm 12.45^{\mathrm{c}}$ \\
\hline & 10 & $24.61 \pm 6.03^{\mathrm{a}}$ & $19.58 \pm 4.18^{b}$ & $14.75 \pm 11.46^{\mathrm{c}}$ & $17.15 \pm 7.79^{b}$ \\
\hline & 24 & $33.91 \pm 6.25^{\mathrm{a}}$ & $29.88 \pm 10.19^{b}$ & $25.64 \pm 4.45^{\mathrm{c}}$ & $27.00 \pm 7.93^{\mathrm{bc}}$ \\
\hline \multirow{4}{*}{ Lactate } & 0 & $0.08 \pm 0.05$ & $0.06 \pm 0.02$ & $0.08 \pm 0.04$ & $0.05 \pm 0.01$ \\
\hline & 5 & $2.21 \pm 1.32^{\mathrm{a}}$ & $4.35 \pm 2.03^{b}$ & $2.75 \pm 2.71^{\mathrm{a}}$ & $2.26 \pm 0.70^{\mathrm{a}}$ \\
\hline & 10 & $1.93 \pm 1.05^{\mathrm{a}}$ & $4.01 \pm 2.42^{\mathrm{b}}$ & $1.65 \pm 0.85^{\mathrm{a}}$ & $1.24 \pm 0.33^{\mathrm{a}}$ \\
\hline & 24 & $1.99 \pm 1.69$ & $0.80 \pm 1.24$ & $2.15 \pm 1.90$ & $1.38 \pm 0.30$ \\
\hline
\end{tabular}

$\mathrm{ND}$, not detected. Data are presented as means $\pm \mathrm{SD}(\mathrm{n}=6)$. Different superscripted letters across rows indicate statistically significant differences $(p<0.05)$. 
Functional Foods in Health and Disease 2017; 7(10): 833-848

Page 840 of 848

Table 1. In vitro investigation of the impact of OFSP purees on the human faecal microbiota using $\mathrm{pH}$ controlled batch fermentations

\begin{tabular}{|c|c|c|c|c|c|c|c|c|c|c|c|c|c|c|c|}
\hline \multirow{2}{*}{ Substrate } & \multicolumn{5}{|c|}{ Total bacteria } & \multicolumn{5}{|c|}{ Bacteroides } & \multicolumn{5}{|c|}{ Bifidobacteria } \\
\hline & $\mathbf{0}$ & 5 & 10 & 24 & $\Delta_{\max (\mathrm{t} 0)}$ & $\mathbf{0}$ & 5 & 10 & 24 & $\begin{array}{r}\Delta_{\mathrm{m}} \\
\mathrm{ax}(0)\end{array}$ & $\mathbf{0}$ & 5 & 10 & 24 & $\Delta_{\max (\mathrm{t} 0)}$ \\
\hline FOS & 10.07 & 11.16 & 11.19 & 11.43 & 1.36 & 8.55 & 8.70 & 9.04 & 9.90 & 1.35 & 8.29 & 10.55 & 10.90 & 10.69 & 2.61 \\
\hline Sucrose & 10.65 & 10.61 & 10.73 & 11.39 & 0.74 & 8.09 & 7.19 & 9.30 & 9.90 & 1.82 & 8.63 & 10.25 & 10.47 & 10.52 & 1.89 \\
\hline Rp puree & 10.43 & 11.21 & 11.55 & 11.52 & 1.12 & 7.63 & 8.89 & 9.78 & 10.23 & 2.60 & 8.21 & 10.67 & 10.85 & 10.76 & 2.63 \\
\hline Op puree & 10.46 & 11.08 & 11.33 & 11.40 & 0.94 & 6.94 & 8.68 & 9.60 & 10.24 & 3.30 & 8.32 & 10.54 & 10.91 & 10.59 & 2.59 \\
\hline FOS & 8.63 & 10.20 & 9.27 & 11.99 & 3.36 & 7.78 & 8.33 & 8.63 & 9.63 & 1.85 & 9.29 & 10.06 & 10.13 & 10.73 & 1.44 \\
\hline Sucrose & 8.46 & 8.06 & 8.33 & 10.66 & 2.20 & 7.34 & 7.47 & 7.28 & 9.67 & 2.33 & 8.94 & 8.71 & 10.04 & 11.18 & 2.24 \\
\hline Rp puree & 9.18 & 8.10 & 9.72 & 9.56 & 0.54 & 8.33 & 7.08 & 9.84 & 8.77 & 1.51 & 9.44 & 9.26 & 10.76 & 9.50 & 1.32 \\
\hline Op puree & 7.60 & 8.09 & 9.52 & 10.48 & 2.88 & 6.73 & 7.43 & 8.40 & 8.66 & 1.93 & 7.66 & 9.08 & 12.82 & 9.55 & 5.17 \\
\hline FOS & 8.69 & 8.77 & 8.53 & 8.80 & 0.11 & 8.52 & 8.34 & 8.55 & 8.60 & 0.07 & 8.90 & 9.97 & 11.71 & 9.02 & 2.81 \\
\hline Sucrose & 8.48 & 9.17 & 8.46 & 8.72 & 0.69 & 8.15 & 8.58 & 8.01 & 8.51 & 0.43 & 8.72 & 10.26 & 10.67 & 9.46 & 1.95 \\
\hline Rp puree & 8.54 & 9.28 & 8.49 & 9.86 & 1.32 & 8.19 & 8.78 & 8.74 & 8.20 & 0.59 & 8.83 & 10.11 & 9.69 & 9.20 & 1.27 \\
\hline Op puree & 7.33 & 8.36 & 8.47 & 8.65 & 1.32 & 7.24 & 8.04 & 8.76 & 8.35 & 1.52 & 8.58 & 9.07 & 9.53 & 9.07 & 0.95 \\
\hline FOS & 8.87 & 10.53 & 10.45 & 10.44 & 1.66 & 8.14 & 9.18 & 9.88 & 9.66 & 1.74 & 7.77 & 10.30 & 10.43 & 10.46 & 2.69 \\
\hline Sucrose & 9.75 & 10.34 & 10.34 & 10.10 & 0.59 & 9.00 & 9.54 & 9.84 & 9.35 & 0.84 & 8.65 & 10.39 & 9.82 & 10.06 & 1.74 \\
\hline Rp puree & 9.77 & ND & 10.23 & 10.00 & 0.45 & 9.03 & 9.53 & 9.52 & 9.40 & 0.49 & 8.53 & 10.22 & 9.83 & 10.28 & 1.75 \\
\hline Op puree & 9.37 & ND & 10.45 & 10.19 & 1.08 & 8.65 & 9.23 & 9.46 & 9.39 & 0.81 & 8.26 & 10.05 & 10.32 & 10.39 & 2.13 \\
\hline FOS & 9.40 & 9.27 & 9.21 & 10.00 & 0.60 & 8.81 & 9.11 & 8.76 & 9.35 & 0.54 & 8.84 & 9.56 & 9.27 & 9.95 & 1.12 \\
\hline Sucrose & 9.36 & 9.63 & 9.81 & 9.78 & 0.45 & 8.73 & 9.19 & 9.17 & 9.26 & 0.53 & 8.66 & 9.74 & 9.87 & 9.70 & 1.21 \\
\hline Rp puree & 9.24 & 9.95 & 9.19 & 9.77 & 0.70 & 8.69 & 8.43 & 9.05 & 9.59 & 0.90 & 8.55 & 9.83 & 9.09 & 9.84 & 1.29 \\
\hline FOS & 10.14 & 10.57 & 10.08 & 10.01 & 0.44 & 8.71 & 8.82 & 8.48 & 8.78 & 0.10 & 9.28 & 10.23 & 10.30 & 10.32 & 1.05 \\
\hline Sucrose & 8.84 & 10.71 & 10.77 & 10.78 & 1.95 & 7.92 & 8.24 & 7.77 & 8.26 & 0.34 & 8.46 & 10.35 & 10.44 & 9.95 & 1.98 \\
\hline Rp puree & 9.08 & 9.78 & 10.48 & 10.30 & 1.40 & 8.12 & 8.23 & 7.43 & 7.43 & 0.11 & 8.72 & 9.66 & 10.40 & 10.08 & 1.68 \\
\hline Op puree & 8.49 & 10.55 & 10.60 & 10.76 & 2.27 & 7.61 & 8.16 & 8.97 & 9.03 & 1.42 & 8.38 & 10.56 & 10.85 & 10.81 & 2.47 \\
\hline
\end{tabular}

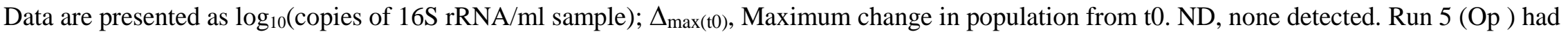
experimental error 
Table 3. Maximum change in population levels compared to baseline $\left(\mathrm{t}_{0}\right)$ levels during $\mathrm{pH}$ controlled batch fermentations

\begin{tabular}{|l|l|c|c|c|c|c|c|c|}
\hline Bacteria & Substrate & $\begin{array}{c}\text { Run } \\
\mathbf{1}\end{array}$ & $\begin{array}{c}\text { Run } \\
\mathbf{7}\end{array}$ & $\begin{array}{c}\text { Run } \\
\mathbf{3}\end{array}$ & $\begin{array}{c}\text { Run } \\
\mathbf{4}\end{array}$ & $\begin{array}{c}\text { Run } \\
\mathbf{5}\end{array}$ & $\begin{array}{c}\text { Run } \\
\mathbf{6}\end{array}$ & $\begin{array}{c}\text { Average } \pm \text { S } \\
\text { D }\end{array}$ \\
\hline \multirow{5}{*}{ Total } & FOS & 1.36 & 3.36 & 0.11 & 1.66 & 0.60 & 0.44 & $1.25 \pm 1.18$ \\
\cline { 2 - 9 } & Sucrose & 0.74 & 2.20 & 0.69 & 0.59 & 0.45 & 1.95 & $1.10 \pm 0.76$ \\
\cline { 2 - 9 } & Rp puree & 1.12 & 0.54 & 1.32 & 0.45 & 0.70 & 1.40 & $0.92 \pm 0.41$ \\
\cline { 2 - 9 } & Op puree & 0.94 & 2.88 & 1.32 & 1.08 & ND & 2.27 & $1.70 \pm 0.84$ \\
\hline \multirow{5}{*}{ Bacteroides } & FOS & 1.35 & 1.85 & 0.07 & 1.74 & 0.54 & 0.10 & $0.94 \pm 0.81$ \\
\cline { 2 - 9 } & Sucrose & 1.82 & 2.33 & 0.43 & 0.84 & 0.53 & 0.34 & $1.05 \pm 0.83$ \\
\cline { 2 - 9 } & Rp puree & 2.60 & 1.51 & 0.59 & 0.49 & 0.90 & 0.11 & $1.03 \pm 0.90$ \\
\cline { 2 - 9 } & Op puree & 3.30 & 1.93 & 1.52 & 0.81 & ND & 1.42 & $1.80 \pm 0.93$ \\
\hline \multirow{5}{*}{ Bifidobacterium } & FOS & 2.61 & 1.44 & 2.81 & 2.69 & 1.12 & 1.05 & $1.95 \pm 0.83^{\mathrm{a}}$ \\
\cline { 2 - 9 } & Sucrose & 1.89 & 2.24 & 1.95 & 1.74 & 1.21 & 1.98 & $1.84 \pm 0.35^{\mathrm{a}}$ \\
\cline { 2 - 9 } & Rp puree & 2.63 & 1.32 & 1.27 & 1.75 & 1.29 & 1.68 & $1.66 \pm 0.52^{\mathrm{a}}$ \\
\cline { 2 - 9 } & Op puree & 2.59 & 5.17 & 0.95 & 2.13 & ND & 2.47 & $2.66 \pm 1.54^{\mathrm{b}}$ \\
\hline
\end{tabular}

Data are presented as $\log _{10}$ (copies of $16 \mathrm{~S} \mathrm{rRNA} / \mathrm{ml}$ sample). Different superscripted letters between substrates indicate statistically significant differences $(p<0.05)$.

Bifidobacteria: Although the bifidobacterial levels were exceptionally high, probably due to the probes inability to differentiate the species, the white milky morphological shape characteristic of bif bacteria was clearly observable, demonstrating the ability of OFSP purees to support the growth of bifidobacteria (Table 1). On average, bifidobacterial counts increased by $1.66-2.66\left(\log _{10}[\right.$ copies $\left./ \mathrm{ml}]\right)$, with significant differences $(p<0.05)$ between the substrates; Op puree recording the highest maximum change (Table 3). Studies with other non-digestible carbohydrates reported increases in bifidobacteria up to $24 \mathrm{hr}$ of fermentation [51-54]. Bifidobacterium species have been reported to be greatly beneficial to gastrointestinal health by inhibiting pathogen growth, stimulating the immune system and production of vitamin B complex [55-56].

Further investigation of other bacterial populations (i.e. different Clostridium clusters, lactobacillus, fusobacteria, Coriobacteriia, and Faecalibacterium) is required to better understand the overall impact of OFSP purees on the faecal microbiota, and thereby their comprehensive potential in gut modulation/prebiotic activity and possible health benefits. In addition, future work should compare different universal primers and/or develop more robust universal primer sets for accurately determining the total bacterial load using qPCR.

\section{Effects of OFSP puree batch fermentation on production of SCFA}

Total SCFA: Total SCFA significantly $(p<0.05)$ increased throughout the $24 \mathrm{hr}$ fermentation in all vessels (Table 2). However, the only statistically significant difference $(p<0.05)$ was observed between FOS and the other different substrates at $\mathrm{t} 24$. The predominant SCFA seen during the batch fermentations were acetate and butyrate (t10 and t24). High levels of organic 
acid increase the acidity of the colon and have been reported to have various health benefits such as inhibiting growth of pathogen and increasing bioavailability of minerals [57-58].

Acetic acid: Acetate levels increased significantly over time in all the four substrates (Table 2 ), by eight to ten-fold during the first 5 hours. Concentrations were significantly higher for FOS and Rp puree at t5 compared to Op puree and sucrose $(p<0.05)$. All four substrates resulted in $\sim 40 \mathrm{mmol} / \mathrm{ml} \mathrm{levels} \mathrm{of} \mathrm{acetate} \mathrm{at} \mathrm{the} \mathrm{end} \mathrm{of} \mathrm{fermentation} \mathrm{(t24).} \mathrm{Acetic} \mathrm{acid} \mathrm{is} \mathrm{not} \mathrm{only}$ beneficial as a strong organic acid for reduction of $\mathrm{pH}$ that causes inhibition of growth of pathogens, as it is also metabolized systemically in brain and muscle tissues generating energy for host cells [59].

Butyric acid: Butyrate levels also increased during the entire experimental fermentation period, from minimal or non-detectable levels at t0 to $25-34 \mathrm{mmol} / \mathrm{ml}$ at t24 (Table 2). Significant differences $(\mathrm{p}<0.05)$ profiles were observed in production of butyrate in the different substrates (on average and between runs; e.g. greater variation was seen across different runs for OFSP purees during the first ten hours than for control substrates). Overall, FOS had the highest level of butyrate while Rp puree the lowest (Table 3). Recent studies have demonstrated the relationship between the gut microbiota and metabolites especially butyrate and some behavioural disorders (depression, anxiety, and schizophrenia [60]), obesity [61], and infectious diseases due to a disturbed gut barrier [62].

Propionic acid: Propionate levels increased significantly $(p<0.05)$ for all the four substrates throughout the experimental period, although OFSP purees elicited significantly higher levels at $t 5$ and t10 compared to the control substrates (Table 3 ). With the exception of sucrose (which was significantly lower), propionate levels averaged $\sim 18 \mathrm{mmol} / \mathrm{ml}$ at the end of fermentation (t24). It is worth noting that the changes in propionate levels did not appear to correlate to changes in Bacteroides levels, as recently reported (2016) by Chung et al. [63]. Propionate is a substrate for energy production in the liver and has several proposed health benefits such as weight loss, anti-inflammatory, and cholesterol-lowering properties, immunity and brain development [64 -66] as well as associations with reduced risks of diseases, such as diabetes, obesity, and inflammatory diseases and autism spectrum disorders [67-70].

Formic acid: Formate levels initially increased for all substrates, with maximum levels seen at t5 (Table 2). Afterwards, formate levels declined with significantly different concentrations $(p<0.05)$ as recorded between the different substrates at t10 and levels similar to starting levels seen at 24 . Op puree recorded the lowest $\mathrm{t} 24$ levels of formic acid, which was significantly different $(p<0.05)$ to that of all other substrates. Formic acid is a strong organic acid that can impact on acidity level in the gut, thus killing pathogens.

Lactic acid: Lactate levels demonstrated the smallest changes in SCFA during the 24 hours fermentation of the SCFA detected (Table 2). Lactate increased in the first 5 hours, with significantly higher levels seen for sucrose compared to all other substrates. Similar to formate, lactate levels decreased (by varying levels) afterwards to t24. Although the amount of lactic acid is low in human blood $(1-2 \mathrm{mmol} / \mathrm{L})$ during rest, some studies suggests its importance during early stages of brain development and in the gut by reduction of infection/inflammation and lowering levels of lipopolysaccharides (LPS) in immunity enhancement and cancer prevention [71-72]. 
Confirmation of prebiotic activity by composition analysis and characterization of OFSP puree for ingredients such as dietary fibre, resistant starch, and oligosaccharides and/or use of different biomarkers such as immunological changes, inflammatory mediators, serum lipid levels, genotoxicity, toxicity, and cognitive function would provide a more accurate way of monitoring and relating prebiotic food ingredients to healthy [73]. However, the best selective validation method which requires vigorous ethical consensus is in vivo study using human or animal by administering sweet potatoes grown in stable ${ }^{13} \mathrm{C}$ isotope, followed by quantification of SCFA in plasma or faeces and molecular technology for profiling the microbes [74-75].

\section{CONCLUSIONS}

Bacterial profiles and SCFA levels varied over the entire experimental fermentation time in the two varieties of OFSP and controls. Since increases were observed in the two well-known biomarkers of a healthy gut, bifidobacteria, and SCFA metabolites (especially butyrate), the current research clearly suggests there is potential to promote gut health, although further investigation on bifidogenic effect and pathogen inhibition is warranted. Despite the interindividual variation (whether it be age-related or inter-ethnical) of the gut microbiota and hence the baseline composition of bacterial population, the results suggest ability of the OFSP purees to positively modulate gut microbiota. However, further investigation is warranted for proving prebiotic activity of OFSP by profiling more beneficial gut bacteria (including lactobacilli and bifidobacteria) such as butyrate producers e.g. Eubacterium rectale while demonstrating inhibition of growth of pathogenic bacteria, such as clostridia (e.g., Clostridium difficile and C. perfringens) and Enterobacteriaceae in addition to possibly measuring prebiotic index (PI). It is also recommended to conduct biochemical analysis of OFSP to determine if ingredients with the potential to elicit prebiotic/beneficial effects (for example, non-starch polysaccharides) are present in addition to in vivo human feeding studies

List of Abbreviations: FOS, Fructooligosaccharide; GI, Gastrointestinal; GMM, Gut model media; LPS, Lipopolysaccharides; OFSP, Orange fleshed sweet potato; PBS, Phosphatebuffered saline; qPCR, Quantitative polymerase chain reaction; SCFA, Short chain fatty acid.

Competing Interests: The authors declare that there is no conflict of interest associated with this manuscript.

Author Contributions: Dr. Muchiri conducted the research study and wrote the manuscript while Prof McCartney supported and offered guidance in laboratory experiments and edition of manuscript.

Acknowledgements and Funding: The authors wish to thank Schlumberger Foundation, Faculty for the Future who funded the research work and Qianjun Ye, for assisting in partial fulfilment of her M.Sc. degree.

\section{REFERENCES}

1. Connolly ML, Tuohy KM, Lovegrove JA: Wholegrain oat-based cereals have prebiotic potential and low glycaemic index. British Journal of Nutrition 2012, 12:2198-206.

2. Menne E, Guggenbuhl N, Roberfroid M: Fn-type chicory inulin hydrolysis has a prebiotic effect in humans. Journal of Nutrition 2000 130: 1197-1199. 
3. Tuohy KM, Kolida S, Lustenberger AM:. The prebiotic effects of biscuits containing partially hydrolysed guar gum and fructo-oligosaccharides - a human volunteer study. British Journal of Nutrition 2001a, 86: 341-348

4. Cummings JH, Macfarlane GT: The control and consequences of bacterial fermentation in the human colon. Journal of Applied Bacteriology 1991, 70 (6): 443-459.

5. Gibson GR, Probert HM, Van Loo JAE, Roberfroid MB: Dietary modulation of the human colonic microbiota: Updating the concept of prebiotics. Nutrition Research Reviews 2004, 17: 257-275.

6. ISAPP: International Scientific Association of Probiotics and Prebiotics (ISAPP) 6th Meeting. Ontario, Canada; 2008.

7. Gibson GR, Scott KP, Rastall RA, et al: Dietary prebiotics: current status and new definition. Food Science and Technology Bulletin: Functional Foods 2010, 7 (1): 1-19.

8. FAO, Food and Agriculture Organization of the United Nations: Guidelines for the Evaluation of Probiotics in Food. A joint FAO/WHO Working Group Report on Drafting Guidelines for the Evaluation of Probiotics in Food. Ontario, Canada: FAO; 2002.

9. Ehler JT: Sweet potato nutrition: Sweet potato ranks Number One in nutrition. [http://www. Food reference. com/html/sweet-pot-nutrition.html]

10. Jaarsveld PJ, de Wet M, Harmse E, Nestel P, Rodriguez-Amaya DB: Retention of $\beta$ carotene in boiled, mashed orange-fleshed sweet potato. Journal of Food Composition and Analysis 2006, 19: 321-329

11. Truong VD, Biermann CJ, Marlett JA: Simple sugars, oligosaccharides, and starch concentrations in raw and cooked sweet potato. Journal of Agricultural and Food Chemistry 1986, 34: 421-425.

12. Bovell-Benjamin AC: Sweet potato: A review of its past, present, and future role in human nutrition. Advances in Food and Nutrition Research 2007, 52: 1-48.

13. Cummings JH, Macfarlane GT: The control and consequences of bacterial fermentation in the human colon. Journal of Applied Bacteriology 1991, 70 (6): 443-459.

14. Rosendale D, Cookson A, Roy N, Vetharaniam I: Opportunities for predictive modelling and gut health. Conceptually exploring an in silico tool for quantifying the benefits of dietary fibre consumption. Agro Food Industry Hi-Tech 22 2011, 6: 18-22.

15. Ndolo PJ, Nungo RA, Kapinga RE, Agili S: Development and Promotion of OrangeFleshed Sweet potato Varieties in Western Kenya. Proceedings of the 13th ISTRC Symposium; 2007: 689-95.

16. K'osambo LM, Carey EE, Misra AK, Wilkes J, Hagenimana V: Influence of age, farming site, and boiling on provitamin A content in sweet potato (Ipomoea batatas (L.) Lam.) storage roots. Journal of Food Composition and Analysis: an Official Pulication of the United Nations University, International Network of Food Data Systems 1998, 11: 305-321.

17. Serenje GI, Mwala SM: Variation in micronutrient content of orange-fleshed sweet potato varieties grown in different environments. Second RUFORUM Biennial Meeting. Entebbe, Uganda; 2010.

18. Ukom A, Ojimelukwe P, Okpara D: Nutrient composition of select sweet potato [Ipomoea batatas (L. lam)] Varieties as influenced by different level of nitrogen fertilizer application. Pakistan Journal of Nutrition 8 (11) 2009: 1791-1795. 
19. Macfarlane GT, Gibson GR, Cummings JH: Comparison of fermentation reactions in different regions of the human colon. Journal of Applied Bacteriology 1992, 72: 56-62.

20. Macfarlane GT, Macfarlane S, Gibson GR: Validation of a three-stage compound continuous culture system for investigating the effect of retention time on the ecology and metabolism of bacteria in the human colon. Microbial Ecology 1998, 35: 180-187

21. Cummings JH, Macfarlane GT: Role of intestinal bacteria in nutrient metabolism. Clinical Nutrition 1997, 16 (1): 3-11.

22. Guarner, FMD, Malagelada JR: Gut flora in health and disease. Lancet 2003, 361; 512519.

23. Andersson HB, Ellegard LH, Bosaeus IG: Non digestibility characteristics of inulin and oligofructose in humans. Journal of Nutrition 1999, 129: 1428S-1429S.

24. Coussement, PAA: Inulin and oligofructose: Safe intakes and legal status. Journal of Nutrition 1999, 129: S1412-S1417.

25. Kolida S, Tuohy KM, Gibson GR: Prebiotic effects of inulin and oligofructose. British Journal of Nutrition 2007, 87: S193-S197.

26. Tuohy KM, Finlay RK, Wynne AG, Gibson GR: A human volunteer study on the prebiotic effects of HP-inulin - gut bacteria enumerated using fluorescent in situ hybridisation (FISH). Anaerobe 2001b, 7: 113-118.

27. Tuohy KM, Ziemer C, Klinder A, Knobel Y, Pool-Zobel BL, Gibson GR: A human volunteer study to determine the prebiotic effects of lactulose powder on human colonic microbiota. Microbial Ecology in Health and Disease 2002, 14: 165-173.

28. Ramirez-Farias C, Slezak K, Fuller Z, Duncan A, Holtrop G, Louis P: Effect of inulin on the human gut microbiota: stimulation of Bifidobacterium adolescentis and Faecalibacterium prausnitzii. British Journal of Nutrition 2009, 101: 541-550.

29. Rastall RA, Gibson GR, Gill HS, Guarner F, Klaenhammer TR, Pot B, Reid GR, Rowland IR, Sanders ME: Modulation of the microbial ecology of the human colon by probiotics, prebiotics and synbiotics to enhance human health: an overview of enabling science and potential applications. FEMS Microbiology Ecology 2005, 52: 145-152.

30. Roberfroid MB, Gibson GR, Hoyles L, et al.: Prebiotic effects: metabolic and health benefits. British Journal of Nutrition 2010, 104: S1-S63.

31. Scholz-Ahrens KE, Schaafsma G, van den Heuvel, EGHM, Schrezenmeir J: Effects of prebiotics on mineral metabolism. American Journal of Clinical Nutrition 2001, 73 (suppl): 459S-464S.

32. Gibson GR, McCartney AL, Rastall RA: Prebiotics and Resistance to Gastrointestinal Infections, British Journal of Nutrition 2006, 93: S31-S34.

33. Liong, MT: Roles of probiotics and prebiotics in colon cancer prevention: postulated mechanisms and in vivo evidence. International Journal of Molecular Sciences 2008, 9: 854-863.

34. Cummings JH, Macfarlane GT: The control and consequences of bacterial fermentation in the human colon. Journal of Applied Bacteriology 1991, 70 (6): 443-459.

35. Cummings JH: Short chain fatty acids. In: Gibson, G.R. and Macfarlane, G.T. Human Colonic Bacteria: Role in Nutrition, Physiology and Pathology. Boco Raton, FL: CRS Press; 1995: 101-130.

36. Macfarlane G, Macfarlane S: Models for intestinal fermentation: association between food components, delivery systems, bioavailability and functional interactions in the gut. Current Opinion in Biotechnology 2007, 18 (2): 156-162. 
37. Roberto Berni Canani, Margherita Di Costanzo, Ludovica Leone, Monica Pedata, Rosaria Meli, Antonio Calignano: Potential beneficial effects of butyrate in intestinal and extra intestinal diseases. World Journal of Gastroenterology 2011, 28; 17(12): 1519-1528.

38. Charalampopoulos D, Rastall RA: Prebiotics and Probiotics Science and Technology (Eds.) XLVI, 1262P; 2009.

39. Martens EC, Chiang HC, Gordon JI: Mucosal glycan foraging enhances fitness and transmission of a saccharolytic human gut bacterial symbiont. Cell Host Microbe 2008, 4 (5): 447-457.

40. Ouwehand A, Salminen S: In vitro adhesion assays for probiotics and their in vivo relevance: a review. Microbial Ecology in Health and Disease 2003, 15: 175-184.

41. Mills DJ, Tuohy KM, Booth J, Buck M, Crabbe MJ, Gibson GR, Ames JM: Dietary glycated protein modulates the colonic microbiota towards a more detrimental composition in ulcerative colitis patients and non-ulcerative colitis subjects. Journal of Applied Microbiology 2008, 105 (3): 706-714.

42. Tuohy KM, Fava F, Viola R: The way to a man's heart is through his gut microbiota Dietary pro- and prebiotics for the management of cardiovascular risk. Proceedings of the Nutrition Society meeting London on 11-12 December 2012; 2014.

43. Ridley SC, Lim M, Heenan S, Bremer P: Evaluation of sweet potato cultivars and heating methods for control of maltose production, viscosity and sensory quality. Journal of Food Quality 2005, 28: 191-204.

44. Macfarlane GT, Macfarlane S, Gibson GR: Validation of a three-stage compound continuous culture system for investigating the effect of retention time on the ecology and metabolism of bacteria in the human colon. Microbial Ecology 1998, 35: 180-187.

45. Walker AW, Ince J, Duncan SH, et al.: Dominant and diet-responsive groups of bacteria within the human colonic microbiota. The ISME Journal 2011, 5: 220-230.

46. Richard AJ, Calder AG, Stewart CS, Smith A: Simulated determination of volatile and non-volatile acidic fermentation products of anaerobic by capillary gas chromatography. Letters in Applied Microbiology 1989: 5-8.

47. Blatchford P, Stoklosinski H, Walton G, Swann J, Gibson G, Gearry R, Ansell J: Kiwifruit fermentation drives positive gut microbial and metabolic changes irrespective of initial microbiota composition. Bioactive Carbohydrates and Dietary Fibre 2015, 6: $37-45$.

48. Chung WSF, Walker AW, Louis P, Parkhill J, Vermeiren J, Bosscher D, Duncan SH, Flink HJ: Modulation of the human gut microbiota by dietary fibres occurs at the species level. BMC Biology 2016, 14: 3.

49. Martens EC, Chiang HC, Gordon JI: Mucosal glycan foraging enhances fitness and transmission of a saccharolytic human gut bacterial symbiont. Cell Host Microbe 2008, 4(5): 447-457.

50. Blatchford P, Stoklosinski H, Walton G, Swann J, Gibson G, Gearry R, Ansell J: Kiwifruit fermentation drives positive gut microbial and metabolic changes irrespective of initial microbiota composition. Bioactive Carbohydrates and Dietary Fibre 2015, 6: 37-45.

51. Manderson K, Pinart M, Tuohy KM, Grace WE, Hotchkiss AT, Widmer W, Yadhav MP, Gibson GR, Rastall RA: In vitro determination of prebiotic properties of 
oligosaccharides derived from an orange juice manufacturing by-product stream. Applied and Environmental Microbiology 2005, 71 (12): 8383-8389.

52. Roberfroid MB, Van Loo JAE, Gibson GR: The bifidogenic nature of chicory inulin and its hydrolysis products. Journal of Nutrition 1998, 128: 11-19.

53. Kolida S, Tuohy KM, Gibson GR: Prebiotic effects of inulin and oligofructose. British Journal of Nutrition 2007, 87: S193-S197.

54. Franck A: Food applications of prebiotics. In Handbook of Prebiotics. Edited by Gibson GR and Roberfroid MB. CRC Press, Boca Raton, USA; 2008: 437-448.

55. Canani RB, Di Costanzo M, Leone L, Pedata M, Meli R, Calignano A: Potential beneficial effects of butyrate in intestinal and extra intestinal diseases. World Journal of Gastroenterology 2011, 28; 17(12): 1519-1528.

56. Rivière A, Selak M, Lantin D, Leroy F De Vuyst L: Bifidobacteria and ButyrateProducing Colon Bacteria: Importance and Strategies for Their Stimulation in the Human Gut. Front Microbiol 2016, (7): 979.

57. Macfarlane S, Macfarlane GT, Cummings JH: Prebiotics in the gastrointestinal tract. Alimentary Pharmacology \& Therapeutics 2006, 24 (5): 701-714.

58. Gibson GR, Scott KP, Rastall RA, et al.: Dietary prebiotics: current status and new definition. Food Science and Technology Bulletin: Functional Foods 2010, 7 (1): 1-19.

59. Cummings JH, Englyst HN: Gastrointestinal effects of food carbohydrate. American Journal of Clinical Nutrition 1995, 61: 938S-945S.

60. Collins SM, Surette M, Bercik P: The interplay between the intestinal microbiota and the brain. Nature Review Microbiology 2012, 10 (11):735-42.

61. Tuohy KM, Fava F, Viola R: The way to a man's heart is through his gut microbiota Dietary pro- and prebiotics for the management of cardiovascular risk. Proceedings of the Nutrition Society meeting London on 11-12 December 2012; 2014.

62. Othman M, Agüero R, Lin HC: Alterations in intestinal microbial flora and human disease. Current Opinion Gastroenterology 2008, 24(1):11-6.

63. Chung WSF, Walker AW, Louis P, Parkhill J, Vermeiren J, Bosscher D, Duncan SH, Flink HJ: Modulation of the human gut microbiota by dietary fibres occurs at the species level. BMC Biology 2016, 14: 3.

64. Kasubuchi M, Hasegawa S, Hiramatsu T, Ichimura A, Kimura I: Dietary gut microbial metabolites, short-chain fatty acids, and host metabolic regulation. Nutrients 2015, (7): 2839-2849.

65. Al-Lahham S, Roelofsen H, Rezaee F, Weening D, Hoek A, Vonk R et al.: Propionic acid affects immune status and metabolism in adipose tissue from overweight subjects. European Journal of Clinical Investigation 2012, 42: 357-364.

66. Macfarlane GT, Gibson GR: Metabolic activities of the normal colonic flora. In: Human Health: The Contribution of Microorganisms. Edited by Gibson SAW. London: Springer; 1994: 17-52.

67. Frye RE, Rose S, Slattery J, MacFabe DF: Gastrointestinal dysfunction in autism spectrum disorder: the role of the mitochondria and the enteric microbiome. Microbial Ecology in Health and Disease 2015, (26): 27458.

68. Frye RE, Rose S, Chacko J, Wynne R, Bennuri SC, Slattery JC, Tippett M, Delhey L, Melnyk S, Kahler SG, MacFabe DF: Modulation of mitochondrial function by the microbiome metabolite propionic acid in autism and control cell lines. Translational Psychiatry 2016, 6(10). 
69. Nicholson JK, Holmes E, Kinross J, Burcelin R, Gibson G, Jia W et al.: Host-gut microbiota metabolic interactions. Science 2012, 336: 1262-1267.

70. Lambeth SM, Carson T, Lowe J, Ramaraj T, Leff JW, Luo L et al.: Composition, diversity and abundance of gut microbiome in prediabetes and type 2 diabetes. Journal of Diabetes and Obesity 2015, 2: 1-7.

71. Riaz Rajoka MS, Shi J, Zhu J, Shao D, Huang Q, Yang H, Jin M: Capacity of lactic acid_bacteria in immunity enhancement and cancer prevention. Applied Microbiology and Biotechnology 2016. [Epub in-print] Review.

72. Tan J, McKenzie C, Potamitis M, Thorburn AN, Mackay CR, Macia L: The role of short-chain fatty acids in health and disease. Advance Immunology 2014, (121): 91119.

73. Rastall RA, Gibson GR: Recent developments in prebiotics to selectively impact beneficial microbes and promote intestinal health. Current Opinion in Biotechnology 2015, 32: 42-46.

74. Delcour JA, Aman P, Courtin CM, Hamaker BR, Verbeke K: Prebiotics, fermentable dietary fiber, and health claims. Advance Nutrition 2016, 7: 1-4.

75. Boets E, Gornand S, Deroover L et al.: Systemic availability and metabolism of colonic-derived short-chain fatty acids in healthy subjects: a stable isotope study. J Physiol 2017, 595: 541-555. 